\title{
3
}

\section{Language communities of the Northern Ryukyus}

\author{
Okinawan, Amami, and Kunigami
}

Patrick Heinrich

\begin{abstract}
Tinsagu nu hana ya Just as the balsam flower
shimisachi ni sumiti has coloured my fingernails

uya nu yushigutu ya the teachings of my parents

chimu ni sumiri have coloured my heart

Tinsagu nu hana (traditional Northern Ryukyuan song, 'The Balsam Flower')
\end{abstract}

\subsection{The Ryukyu Islands and their languages}

The Ryukyus are a long arc of islands of cultural and historic importance, which have long served as a geographical and maritime centre in Asia. Far from being a periphery of East Asia, they are almost equidistant from Japan, China, and Micronesia, located in the middle of the East China Sea. The islands have played a pivotal role in dynamic transcultural flows-shipping, cultural production, trade, and politics-from pre-history, through the Middle Ages to the 21st century. A former tributary state in the Chinese imperial system, the Ryukyus were an independent state for more than four centuries until coming under the control of Japan's Satsuma Domain in 1609. The Ryukyu Kingdom remained officially intact until absorption by the Meiji Government in 1879. War, American occupation (1945-1972), and relentless language standardization/assimilation to Japanese accompanied the deterioration of the Ryukyuan culture.

The Ryukyuan languages form part of the Japonic language family. They Ryukyuan languages are generally divided into two groups: Northern Ryukyuan and Southern Ryukyuan. The influential Okinawan language is about $70 \%$ lexically similar to standard Japanese. Within the Okinawa region, a dialect of Japanese is 
Uchina Yamatuguchi or 'Okinawan Japanese', which is used in conversation as well as in popular music.

\subsection{The Northern Ryukyuan languages}

The group of languages known generically as 'Northern Ryukyuan' is located in the Amami and Okinawan islands of southwestern Japan. Northern Ryukyuan is a vast dialect continuum where as many as 650 different local dialects were spoken in the 20th century. The Northern Ryukyuan dialects differ greatly from those of the Southern Ryukyus. Many Northern Ryukyuan varieties are not mutually intelligible with other areas. The chain of mutual intelligibility has never interrupted across the hundreds of dialects that are still spoken in the northern half of the Ryukyuan Archipelago today. This makes it difficult to distinguish between 'languages' in this part of the Ryukyus. None of the three Northern Ryukyuan languages has a standard variety; this adds to the difficulty of identifying 'languages' there. To add to the difficulties, many speakers of smaller or isolated dialects are drifting to larger and more prestigious dialects, and language proficiency is declining. Six different grammars have been compiled on these varieties, and there are nine dictionaries. The number of such publications is steadily increasing.

In 2009, the third edition of UNESCO's Atlas of the World's Languages in Danger of Disappearing cited 'Eight endangered languages in Japan', six of which were located in the Ryukyus, from north to south, Amami, Kunigami, Okinawa, Miyako, Yaeyama, and Yonaguni. This news was widely reported in the Japanese media. Ten years later, Okinawa Prefecture published 'Ryukyuan Language Textbooks' for elementary and middle school children. There are sections on individual languages (an orthography for the Kunigami language was developed); the textbooks are designed to be used for activities outside the regular school curriculum. The search for an authentic and compelling categorization of Ryukyuan languages is a central concern in Ryukyuan sociolingustics (Heinrich, Miyara and Shimoji 2015). One way is to treat 'northern Ryukyuan' as one language. Conversely, another approach posits a great number of languages. The latter strategy can be seen in the database of Ethnologue-the comprehensive resource on the world's languages. The Ethnologue identifies eight different languages within the Northern Ryukyuan dialect continuum: North Amami, South Amami, Kikai, Tokunoshima, Okinoerabu, Yoron, Kunigami, and Central Okinawan. The three languages proposed by UNESCO are thus a good compromise. Having three languages in the Northern Ryukyus allows for assimilating dialects that are not too distinct from one another under one language roof. At the same time, the conception of three languages - rather than one (Northern Ryukyuan) or two (Amami and Okinawa)-pays tribute to the great number of dialects found in this part of the archipelago (Heinrich and Anderson 2018). The case of how to classify the 
Northern Ryukyuan languages serves as a vivid reminder that 'a language' is ultimately an artefact and not some sort of 'natural entity' that imposes its own boundaries.

\subsection{Northern Ryukyuan languages and Japanese}

Northern Ryukyuan languages are distinct from standard and dialectal Japanese. In order to illustrate some similarities and dissimilarities, consider an example of variation, and contrast it with standard Japanese as well as between Northern Ryukyuan languages. The sentence, 'I am going to the fields, but where are you going?' has the subsequent forms (in the following <'> represents a glottal stop):

(1) Japanese (standard variety)

Watashi-wa hatake-e iku-kedo anata-wa doko-e iku-no-ka?

(2) Amami (Ura variety)

Wan-ya hatee-ttshi ikyun-ban 'ya-ya da-ttshi ik'yun-yoo?

(3) Kunigami (Nakijin variety)

Wan-ya pharu-tshi itshuu-shiga 'yaa-ya daa-tshi itshu-ga?

(4) Okinawan (Shuri variety)

Wannee haru-nkai itshu-shiga 'yaa-ya maa-nkai itshu-ga?

We can see in these three examples the difference within Northern Ryukyuan with regard to the phonemic systems and morphosyntax. In Nakijin-Kunigami we find the retention of the proto-Japonic/p/in pharu (field) whose cognates are hatee and haru in Ura-Amami and Shuri-Okinawan, respectively. Ura-Amami also features a centralized vowel/ë/which is absent in the two other Northern Ryukyuan varieties of our example above. Morphosyntactically we see that Shuri-Okinawan is more on the 'synthetic end' of agglutinative language typology in that it merges wan (first person singular pronoun) and the subject particle $y a$ to wannee. With regard to morphology, we see the allative marker $n k a i$ in Shuri-Okinawan. Yet, the lexicon is composed of cognates and this allows for some degree of mutual intelligibility, in particular when the varieties are written down for analysis. In some Southern Ryukyuan varieties, 'to go' would not involve cognates of Japanese iku such ikyun, itshuu, itshu as in Northern Ryukyuan but would be harun (Miyara-Yaeyaman) or hirun (Yonaguni).

\subsection{The sociolinguistic situation of Northern Ryukyuan languages}

Talk about the 'vitality' of a language only arises when the language is not well. Placed in a healthy language ecology, languages thrive, develop, and expand. This is no longer the case for Northern Ryukyuan. The ecology is hostile. The retreat 
of the languages from domains such as neighbourhood and family in the 1950s and 1960s meant that the languages have fossilized in those domains. Though some noteworthy linguistic innovation has taken place, the shift from Northern Ryukyuan to Japanese in the public domain is inexorable. In areas such as education, work, publication, or government, from the 1880s onwards, much of the language once used there is now lost. Language shift results in language loss. Northern Ryukyuan varieties have shrunk. The languages have diminished in other ways. We find only part or no proficiency in honorific language today. This is a problem for the use of Northern Ryukyuan languages because polite registers are usually indispensable when talking to elderly community members or family. For example, informants born in the 1950s on Okinoerabu Island where Kunigami is spoken reported the following reactions (Gijs van de Lubbe, personal correspondence):

- 'When I said something in plain language, mum would say, "Did you give birth to me or did I give birth to you?"

- 'Speaking dialect to older people is embarrassing because I don't know how to speak honorific language. My parents would always scold me for that, so now I just speak Japanese to older people.'

These vignettes illustrate that the inability to speak appropriate registers results in a shift to Japanese. In that way, it is impossible for the non-fully proficient to acquire more adequate skills. Language shift and language loss form a vicious circle (Heinrich 2018, Heinrich and Ishihara 2018).

Increased contact between local communities and decreased use of Northern Ryukyuan has also resulted in the loss of local varieties. While dialectologists differentiate between 650 local dialects, many are no longer spoken. Consider the great many variants for 'slug' that were collected only in Okinawa City from informants born during the Meiji period (1868-1912): amadajaa, maidaimushi, andamusaa, andamushi, anramusa, hoomimushi, judajaa, judaajamushi, judaimusa, judaimushi, judaajaa, juraimushii. Today, most Okinawan speakers call 'slug' andamusaa. Local variation has sharply decreased. Dialect extinction and drift to larger dialects is a prominent phenomenon in Northern Ryukyuan languages from the 1950 onwards.

Loss of proficiency and language structures, registers, and styles implies new diversification. This takes the form of mixed languages and codes, which are very popular among the younger generation of the Northern Ryukyus. Examples of such kind of language innovation are maasai (delicious), mixing the equivalents Okinawan maasan and Japanese oishii. Likewise, chigaubaa (is it different?) mixes Okinawan aranbaai and Japanese chigau-no (both meaning 'different'), and $d u$ rubaru (being idle) mixes Okinawan durubain and Japanese bonyari-suru (both meaning 'being idle'). These forms must be properly regarded as a 'diversification of Japanese' as the superstrate is always Japanese. It is said that middle-aged 
and older speakers use the Northern Ryukyuan varieties differently, implying interference from Japanese in middle-aged speech. The young generation mostly no longer speak Northern Ryukyuan.

The sociolinguistic situation today is such that one commonly encounters statements such as 'dialect $\mathrm{X}$ is no longer spoken' or 'I speak dialect X, but I am too young to know everything about it.' None of this is measured in descriptions of language vitality. The most important factors for language vitality are not only the age of the speakers and the time when natural intergenerational language transmission was interrupted but also the number of speakers. UNESCO's Atlas of the World's Languages in Danger of Disappearing used the results of the author's 2004 and 2005 surveys for the Ryukyuan languages. In that period, I held the Northern Ryukyuan languages to be 'definitely endangered'. In the absence of a restoration of natural language transmission or the establishment of Ryukyuan in school education, the situation is ever more critical today. For example, Amami is today 'severely endangered' and Kunigami and Okinawa are also moving towards this stage.

Language attitudes have improved. Most local residents recognize Northern Ryukyuan varieties as an important cultural heritage. The prospects for Okinawan are best. It is the largest of the Northern Ryukyuan languages; it is most often used in new domains such as the internet or podcast. It has the highest prestige and can draw on the support of five universities in the territory where it is traditionally spoken, versus one university for Kunigami and none for Amami.

\subsection{Language, culture, and community}

Languages serve to communicate. Among the countless things communicated are values, mores, and attitudes of speakers. Language is a tool of communication and a means to do things and be someone. It is part of culture and a maker of belonging. This is reflected in the Okinawa proverb kutuba washiree nee, kuni n washitiyunkuni washirii nee, 'uya $n$ washiriyun (if you forget your language, you also forget your country-if you forget your country, you also forget your parents).

Okinawans say, pointedly, kutuba jin-jikee ('words are precious'). Speakers see their language as a part of who they are. Losing their language is 'a loss' for the communities. Because language is an artefact, it incorporates the surrounding sociocultural and economic environment. Okinawa, for example, has specific vocabulary for its fauna and flora. Katabui denotes a light rain, typical of summer in the Ryukyus. It starts and ends in a few minutes. To complain about katabui or open an umbrella marks you as a cultural outsider. Toponyms also carry ecological information. The poetic name for Okinawa in Okinawan is Uruma. ('Okinawa' was coined in Satsuma and 'Ryukyu' in China). Uruma denotes an island made of coral stone. Local terminology adds precision about the immediate ecology, inhabitants, and their culture. The motacillid, a local bird of Okinawa is called juuhuihui (juu $=$ tail + huihui $=$ swing-swing) in Okinawan. The same information about the 
'swinging tail' is not found in the Japanese equivalent, sekirei. The language also directs you to important values in Okinawan communities. Yiimaaru or yuimaaru means, 'chipping in when help is needed', during harvest, housebuilding, or moving etc. This is contrary to the spirit of self-help. One displays the yiimaru attitude both at home and in public because 'habit at home is habit in public' (yaa naree $d u$ fuka naree). Language endangerment triggers social change. People nowadays lament the weakening of the spirit of yiimaru. This is not coincidental. There is growing interest in the connection between language and well-being.

Language is integral with intangible culture. Traditional Ryukyuan songs are world-famous and are sung in Ryukyuan language. They are linked to local festivals and have their own musical conventions. They celebrate local events, work, humour, local heroes, and circulate local attitudes. The song Tinsagu nu hana ('The Balsam Flower') is known by everyone in the Northern Ryukyus. Of great musical and lyrical beauty, it also carries an important cultural message.

Tinsagu nu hana ya

shimisachi ni sumiti

uya nu yushigutu ya

chimu ni sumiri

Tin nu muribushi ya

yumiba yumarishi ga

uya nu yushigutu ya

yumiyanaran

Yuru harasu funi ya

ninufabushi miati

wan nacheru uya ya

wan du miati
Just as the balsam flower

has coloured my fingernails

the teachings of my parents

have coloured my heart

Although the stars in the sky

can be counted

the teachings of my parents

are infinite

Just as a ship that sails at night

is guided by the North Star

My parents who gave birth to me

guide me and watch over me

Language is needed to sing these lyrics and also to understand, appropriate, and recreate the values expressed in the song. Language loss affects the social fabric. 'It's not only about language, it's about how we want to live', as the Okinawan activist Shinako Oyakawa summarized her ambitions about language revitalization to the author.

Traditional Ryukyuan musical theatre was recognized in 2010 as a UNESCO Intangible Cultural Heritage but listed under the Japanese term kumiodori instead of Okinawan kumiwudui (literally, group dance). There exist more than 60 works of kumiwudui which were created before the Ryukyu Kingdom's annexation by the Japanese nation state. They were created before the Japanese language spread in the Ryukyu Islands. In kumiwudui Okinawan instruments such as the sanshin (a stringed instrument) and kutuu (a harp) are used. The lyrics follow the Okinawan ryu $k a$ poetic metre of $8-8-8-6$ syllables, persuasive evidence for a relisting under the Okinawan-not Japanese-term at UNESCO. 
Ryukyuan languages are tied to everyday life. Ask full speakers when Northern Ryukyuan varieties have an edge over (standard) Japanese and you get responses such as 'when joking', 'when having a good time', 'when getting angry', or 'when scolding someone. Emotions run deep with the local language. To revitalize the local varieties the language-culture nexus is crucial. This is because along with language shift and language loss, the Ryukyuan language-culture nexus is weakening.

\subsection{Language education}

Language education is a problem in Japan when it comes to languages other than Japanese or English. Northern Ryukyuan languages are no exception. Speakers and activists have tried to introduce Ryukyuan languages into the school system. There was support for the idea of Ryukyuan languages in school. The Society for Okinawan Language Revival (Uchinaaguchi fukyū kyōgikai) has advocated the idea of Ryukyuan languages in school since 2000. Surveys by local newspapers report an overwhelming support for maintaining local languages and for involving school education in this objective. When the Ryukyuan Heritage Language Society (Ryūkyū keishoggo kenkyūkai) hosted the 18th annual symposium of the Foundation of Endangered Languages in 2014, the participants formulated a petition to Okinawa Prefecture, Kagoshima Prefecture, and the Agency of Cultural Affairs of the central government, which addresses the problem of Ryukyuan language education. The so-called FEL XVIII Declaration stated:

Whereas:

(1) UNESCO recognizes six Ryukyuan languages spoken in Okinawa Prefecture and Kagoshima Prefecture

(2) UNESCO promotes the teaching of Indigenous languages in school in order to maintain the many benefits of social bilingualism

(3) At present the Ryukyuan languages enjoy no official status and still await their introduction to school

(4) All Ryukyuan language are set to become extinct by 2050 if no counteraction is taken.

The resolutions of the Foundation for Endangered Languages convened in Okinawa for their XVIII conference in 2014 in tandem with members of the Ryukyuan Heritage Language Society were as follows:

(A) the appointment of Ryukyuan languages as second official languages and

(B) their introduction into the school system in Okinawa Prefecture and Kagoshima Prefecture in the belief that they would richly benefit the local communities. Specifically, these policies would: 
(1) transmit and promote a deeper and more adequate reflection on Ryukyuan language, history and culture in education

(2) contribute to communal welfare and self-esteem

(3) strengthen control over Ryukyuan self-image and education

(4) maintain choices for language, knowledge, identity, culture for future generations

(5) recognize Japan's historic and present cultural diversity and promote intercultural tolerance.

The reception of the declaration was confirmed by Okinawa Prefecture, Kagoshima Prefecture, and the Agency of Cultural Affairs-and then nothing happened. This is hardly surprising. There is no transformational support for strengthening Ryukyuan languages and for taking adequate steps in this direction. It may appear as if the Ryukyuan languages are in de facto decline.

Language education is limited to hobby circles, extracurricular activities, local media, and NGO activities. There is a great number of such activities, in particular on Okinawa Island. It is from there that officially supported language and educational policy can depart once it overcomes the unproductive laissez-faire attitude towards language endangerment in the Ryukyus. The slogan, 'Leave your language alone', is not helpful for maintaining Ryukyuan languages and making sure they remain relevant for contemporary society. A helpful strategy would be to not leave the Ryukyuan languages alone but, rather, engage in their adaptation to everyday communicative needs and support for transmission. Schools play a central role in such an endeavour.

\subsection{The future of the north Ryukyuan languages}

That Japanese society is 'in transition' is a familiar trope. Change speeds up at the margins. The case of Northern Ryukyuan, on the one hand, is about the maintenance of three distinct local languages, the strengthening of the local language-culture nexus and the organization of language education in school. In a bigger way, it is also about the future of Japan. The Ryukyuan languages still enjoy a vitality which allows for their revitalization. They are a litmus test to gauge the seriousness of the talk about Japan's multicultural symbiosis (tabunka kyōsei). Ten years after the recognition of the Ryukyuan languages as endangered languages of Japan by UNESCO, there is no transformative change on the side of the government. At the same time, grassroots support or public support in general have surged. The conflict between public attitudes and official language and education policies prevails. It would be good to overcome this conflict because there is nothing to be gained in language extinction. 